\title{
The continuing epidemics of diet-related disease: Environmental drivers of the modern diet and why governments must get involved
}

\author{
Jane Polsky
}

\section{University of Toronto}

In September 2011, New York hosted the first UN General Assembly High-Level Meeting on the prevention and control of non-communicable diseases. This meeting's timing was by no means premature: worldwide, obesity and overweight already cause more deaths than underweight. ${ }^{1}$ Together, obesity and other diet-related diseases, including type 2 diabetes, increasingly pose a major global health burden. Canada is no stranger to this grave public health challenge: rising rates of obesity and diabetes seriously threaten the stability of our public health system., ${ }^{2,3}$

The strikingly rapid rise in rates of obesity and diabetes clearly point to environmental drivers. Considering the environmental causes of these largely preventable dietrelated conditions is thus essential for devising effective public health interventions. Below, I explore several drivers of unhealthy diet within the modern food environment and argue for a more prominent role of governments and policy-led interventions.

The "modern" diet (rich in energy-dense, highly processed foods) is commonly recognized to play a key role in the development and management of both obesity and diabetes. There is a growing consensus among experts that recent profound changes in the global food system (which have shaped the modern diet) have been the dominant drivers of soaring rates of obesity and related diseases. ${ }^{4,5}$ Indeed, our current dietary patterns come as no surprise considering a food supply replete with cheap, highly palatable, and energy-dense foods, along with improved food distribution systems and aggressive food marketing of the least healthy foods. ${ }^{4}$

While food calories and single nutrients (e.g., fats, carbohydrates) currently dominate the conversation about diet and poor health, this narrow focus may be obscuring a highly related issue far more deserving of attention: the consumption of a diet rich in highly processed foods.
One prominent nutritional epidemiologist argues that it is the "ultra-processing" of foods (i.e., transforming raw or minimally processed foods such as milk, oils and sugar into ready-to-eat foods such as cereals and soft drinks, often by adding preservatives and chemical additives) - and much less so the food's nutrient or calorie content - that may be a key factor linking the modern diet with disease. ${ }^{6}$ Indeed, what we don't eat may be most salient for poor health. Diets rich in wholesome, minimally processed foods are consistently linked with lower rates of weight gain and chronic disease. ${ }^{7}$ Yet, ultra-processed foods are widely distributed, heavily marketed and extremely profitable, and are precisely the types of foods that line the shelves of nearly all food (and many non-food) establishments.

Ubiquitous access to unhealthy foods is even more pernicious if we consider the insidious effects of this food landscape on our innate responses to food. A rich evidence base shows that unhealthy food choices and overeating are largely automatic and unconscious responses to a barrage of unappreciated environmental cues. ${ }^{8}$ Such cues include large portions sizes, variety of available foods, and food advertising - all of which consistently boost food intake. The ubiquity of - and our high sensitivity to - such food cues in our daily environments place most food-related behaviours well beyond the realm of conscious, rational choice. In other words, the choice of foods and amount consumed are much less a matter of "free will" than is commonly believed. ${ }^{9}$

In view of this "toxic" food environment and our limited capacity to resist its temptations, we can see a clear disconnect between this reality and the prevailing public health messages to individuals about ways to prevent and manage obesity and diabetes (e.g., simply make healthy food choices). To date, such context-ignoring educational strategies have been largely ineffective and will continue to fail at the population level. In contrast, the most 
sustainable and cost-effective strategies aimed at reversing environmental drivers of diet-related disease will almost always be policy-led and involve various levels and sectors of government. ${ }^{4,5}$ Such strategies could include regulating food advertising, mandating healthy food policies within public institutions, and realigning agricultural policies to incorporate health considerations.

Thus, governments, given their core mandate to protect and promote public health, have a leading role to play in stemming the epidemics of obesity and diabetes by crafting policies to address their environmental roots a view strongly endorsed by the recent UN High-Level Meeting on chronic diseases. ${ }^{10}$ To date, however, the Canadian government (and most governments worldwide) have done little to address this serious problem ${ }^{a}$ and have largely delegated the responsibly for obesity and related diseases to individuals, the private sector and nongovernment organizations. ${ }^{4}$ Undoubtedly, the degree of political difficulty in implementing policy-led interventions will continue be high: reasons for this certainly include the powerful lobby force of food and related industries against any government regulation of the food market. ${ }^{7}$ Yet, the continuing epidemics of obesity and diabetes will not be significantly slowed without political leadership, regulation and investment in research (including evaluation of various policy changes). While obstacles to policy-led actions are considerable, the societal costs of inaction are far more staggering.

${ }^{a}$ Although recent efforts in Canada have been made to ignite a conversation about addressing the social and physical environments that drive preventable chronic diseases (e.g., the 2010 Federal, Provincial and Territorial Framework to curb childhood obesity), very little action has ensued. To this day, Canada still lacks a comprehensive strategy on obesity and related chronic diseases.

\section{References}

1. World Health Organization. Global Health Risks: Mortality and burden of disease attributable to selected major risks. Geneva: WHO, 2009. Available at: http://www.who.int/healthinfo/global_burden_disease/ GlobalHealthRisks_report_full.pdf.

2. Canadian Diabetes Association. An Economic Tsunami: The cost of diabetes in Canada. CDA, December 2009. Available at: http://www.diabetes.ca/ documents/get-involved/FINAL_Economic_Report.pdf.

3. Public Health Agency of Canada and the Canadian Institute for Health Information. Obesity in Canada: A joint report from the Public Health Agency of Canada and the Canadian Institute for Health Information. Ottawa, Ontario: PHAC, $\mathrm{ClHI}, 2011$.

4. Swinburn BA, Sacks G, Hall KD, McPherson K, Finegood DT, Moodie ML, Gortmaker SL. The global obesity pandemic: shaped by global drivers and local environments. Lancet 2011;378(9793):804-14.

5. Gortmaker SL, Swinburn BA, Levy D, Carter R, Mabry PL, Finegood DT, Huang T, Marsh T, Moodie ML. Changing the future of obesity: science, policy, and action. Lancet 2011;378(9793):838-47.

6. Monteiro CA. Nutrition and health. The issue is not food, nor nutrients, so much as processing. Public Health Nutrition 2009;12(5):729-31.

7. Mozaffarian D, Hao T, Rimm EB, Willett WC, Hu F. Changes in diet and lifestyle and long-term weight gain in women and men. New England Journal of Medicine 2011;364(25):2392-404.

8. Cohen DA. Obesity and the built environment: changes in environmental cues cause energy imbalances. International Journal of Obesity 2008;32,Suppl 7:S137-S142.

9. Levitsky DA, Pacanowski CR. Free will and the obesity epidemic. Public Health Nutrition 2011;15(1):126-41.

10. United Nations General Assembly. Political declaration of the High-level Meeting of the General Assembly on the Prevention and Control of Noncommunicable Diseases. New York: UN General Assembly, September 16, 2011.

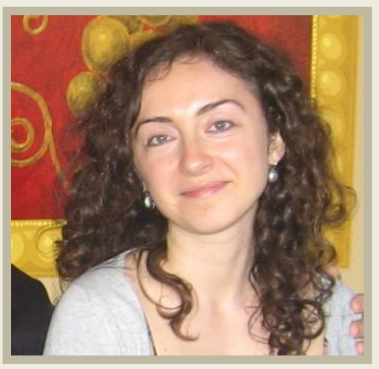

Jane Polsky

I am currently a PhD candidate at the Dalla Lana School of Public Health at the University of Toronto. I also work as a research coordinator with the Centre for Research on Inner City Health at St. Michael's Hospital in Toronto. My main research/work interests include population-level patterns of nutrition, obesity and type 2 diabetes, and their links with the urban environment and socio-economic factors. 